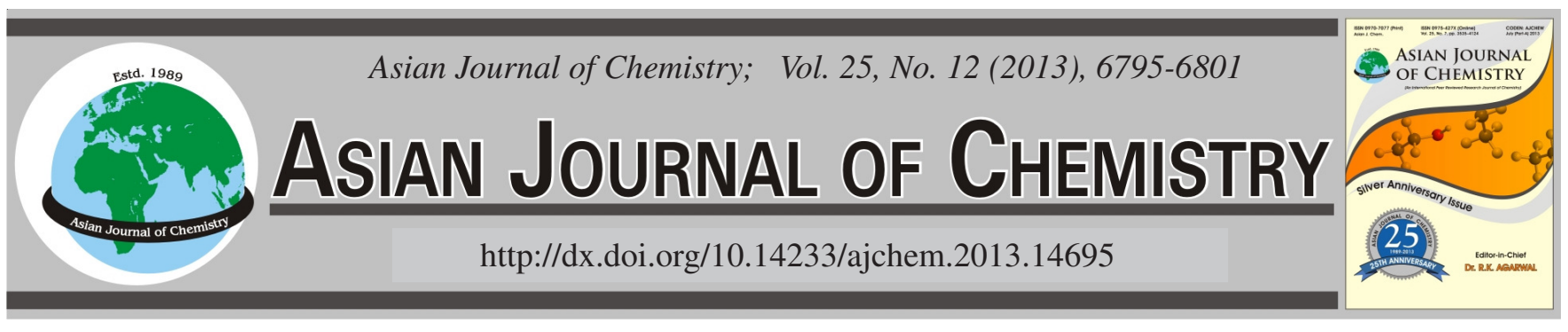

\title{
Properties of $\mathrm{Cu} / \mathrm{ZnO} / \mathrm{Al}_{2} \mathrm{O}_{3}$ Catalysts Modified by Titanium Additives in Synthesis of Methanol from Syngas Using Orthogonal Experimental Design
}

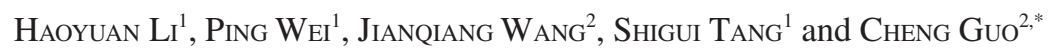

${ }^{1}$ College of Biotechnology and Pharmaceutical Engineering, Nanjing University of Technology, Nanjing 210009, P.R. China

${ }^{2}$ College of Sciences, Nanjing University of Technology, Nanjing 210009, P.R. China

*Corresponding author: Fax: +86 25 83587600; Tel: + 8625 83587448; E-mail: guocheng@ @jut.edu.cn

\begin{abstract}
Ternary $\mathrm{Cu} / \mathrm{ZnO} / \mathrm{Al}_{2} \mathrm{O}_{3}$ catalysts, prepared by reverse co-precipitation, were modified with small amounts of titanium additives using orthogonal experimental design. Precipitating temperature, precipitating mode, additive and precipitating environment were chosen as the main parameters for investigation. Catalytic performance of the catalysts in synthesis of methanol was evaluated in a fixed-bed reactor at $5 \mathrm{MPa}$ and $240{ }^{\circ} \mathrm{C}$. After initial evaluation, the catalysts were used at $350{ }^{\circ} \mathrm{C}$ for $5 \mathrm{~h}$ and then cooled to $240{ }^{\circ} \mathrm{C}$ for re-evaluation. The structure and morphology of the catalysts were studied by differential thermal gravimetric analysis, X-ray diffraction, nitrogen adsorption isotherms, temperature-programmed reduction and transmission electron microscopy. It was found that high precipitating temperature promoted high mixing degrees, which increased initial catalytic yield in methanol synthesis. Combined with the synergistic effects between precursors and additives, a small amount of residual carbonate grains remaining after calcination due to the heat-resistance of rutile nanofibers and octa-potassium titanate whiskers proved beneficial to the catalytic activity.
\end{abstract}

Key Words: Ternary $\mathrm{Cu} / \mathrm{ZnO} / \mathrm{Al}_{2} \mathrm{O}_{3}$ catalysts, Methanol synthesis, Titanium additives, Modification, Orthogonal experimental design.

ᄂ - - - - - - - - - - - - - - - - - - - - - - - - -

\section{INTRODUCTION}

Since the 1960 s, ternary $\mathrm{Cu} / \mathrm{ZnO} / \mathrm{Al}_{2} \mathrm{O}_{3}$ catalysts developed by ICI have been used in industrial synthesis of methanol form syngas, a mixture of $\mathrm{H}_{2}, \mathrm{CO}$ and $\mathrm{CO}_{2}$. Such a heterogeneous process is usually operated at low temperature (200$300{ }^{\circ} \mathrm{C}$ ) and pressure (5-10 MPa). These copper-based catalysts are typically prepared by conventional co-precipitation using nitrates of $\mathrm{Cu}, \mathrm{Zn}$ and $\mathrm{Al}$ as well as alkali bicarbonates or alkali carbonates as basic precipitating agents, then followed by calcination of the precursors and reduction of the calcined products $^{1}$.

Although co-precipitation is an established method to prepare the ternary $\mathrm{Cu} / \mathrm{ZnO} / \mathrm{Al}_{2} \mathrm{O}_{3}$ catalysts, various efforts have still been devoted to improving the performance of the obtained catalysts. One way is to incorporate one or more additives into the ternary $\mathrm{Cu} / \mathrm{ZnO} / \mathrm{Al}_{2} \mathrm{O}_{3}$ catalysts $^{2-5}$. For example, Tagawa et al. ${ }^{6}$, investigated the effect of $\mathrm{TiO}_{2}$-supported copperbased catalysts by in situ Fourier transform infrared spectroscopy (FTIR). The results indicated that formate species developed on the $\mathrm{Cu}$ when supported on $\mathrm{TiO}_{2}$. Furthermore, these formate species on $\mathrm{TiO}_{2}$ could be converted to the surface methoxy species and finally hydrogenated to methanol. Meanwhile, comparable formate on $\mathrm{Al}_{2} \mathrm{O}_{3}$ was inactive.
Another method to improve catalyst activity is to optimize the precipitation process. Some novel precipitation techniques, such as co-precipitation with surfactants and ultrasonic treatment, have been reported. According to Zhao et al. ${ }^{7}$, ultrafine $\mathrm{Cu} / \mathrm{ZnO}$ catalysts could be prepared via the promoted co-precipitation using OP-10. As shown in the results, the precursor contained more aurichalcite and rosasite and the synergistic effect between $\mathrm{Cu}$ and $\mathrm{Zn}$ was strengthened. Compared to catalysts without OP-10 additive, modified catalysts had a smaller particle size, a lower reduction temperature and larger BET and $\mathrm{Cu}$ surface areas. In addition, $\mathrm{Li}$ and Inui ${ }^{8}$ investigated the effect of ultrasonic treatment on methanol synthesis activity of the ternary $\mathrm{Cu} / \mathrm{ZnO} / \mathrm{Al}_{2} \mathrm{O}_{3}$ catalysts. It was found that insonation of the suspension during co-precipitation and aging appreciably enhanced the activity of the catalyst. The enhancement was found to be due to increased formation of a hydrotalcite-like phase in the precursor.

Previous studies using $\mathrm{TiO}_{2}$ additive in copper-based catalysts mainly focused on commercial P25, which consists of $80 \mathrm{wt} \%$ anatase and $20 \mathrm{wt} \%$ rutile. It remains unclear which phase of $\mathrm{TiO}_{2}$ in the catalysts gave a positive effect. In this study, anatase and rutile nanofibers were added to a ternary $\mathrm{Cu} / \mathrm{ZnO} / \mathrm{Al}_{2} \mathrm{O}_{3}$ catalyst. Octa-potassium titanate whiskers were also used as an additive to evaluate the catalytic activity and 
TABLE-1

PARAMETERS AND LEVELS USED IN THE PREPARATION OF THE COPPER-BASED CATALYSTS

\begin{tabular}{lccc}
\hline \multirow{1}{*}{ Parameter } & \multicolumn{3}{c}{ Levels } \\
\cline { 2 - 4 } & Low level (1) & Middle level (2) & High level (3) \\
\hline A: Precipitating temperature & $30^{\circ} \mathrm{C}$ & $50^{\circ} \mathrm{C}$ & $75^{\circ} \mathrm{C}$ \\
B: Precipitating mode & $\mathrm{Cu}, \mathrm{Zn}, \mathrm{Al}$ & $\mathrm{Cu}, \mathrm{Zn} ; \mathrm{Al}$ & $\mathrm{Cu}, \mathrm{Zn} ; \mathrm{Zn}, \mathrm{Al}$ \\
C: Additive & Anatase & Rutile & Octa-potassium titanate \\
D: Precipitating environment & Ultrasound & Surfactant & $-{ }^{\mathrm{a}}$ \\
\hline a High level (3) of factor D indicated the use of conventional co-precipitation without ultrasound or surfactant. &
\end{tabular}

thermal stability of the resulting catalysts in a stainless steel fixed-bed reactor at $5 \mathrm{MPa}$ and $240{ }^{\circ} \mathrm{C}$. The properties of copper-based catalysts obtained by co-precipitation being influenced by parameters such as precipitating temperature, precipitating mode and precipitating environment is well known. To obtain copper-based catalysts with high catalytic performance and investigate the effect of several parameters on the properties of the catalysts, orthogonal experimental design was introduced.

\section{EXPERIMENTAL}

Design of experiments: In general, orthogonal experimental design is a combination of mathematical and statistical techniques to characterize a complicated process and reduce the number of required experiments ${ }^{9,10}$. In this work, four main parameters during co-precipitation were investigated: precipitating temperature (A), precipitating mode (B), additive (C) and precipitating environment (D). A $\mathrm{L}_{9}\left(3^{4}\right)$ orthogonal experimental design was thus performed to optimize the preparation of copper-based catalysts with high catalytic performance. The four factors and their levels are summarized in Table-1. It should be noted that the copper-based catalysts were prepared by reverse co-precipitation, the details of which are shown in Fig. 1. The structure of $\mathrm{L}_{9}\left(3^{4}\right)$ orthogonal design is shown in Table-2.

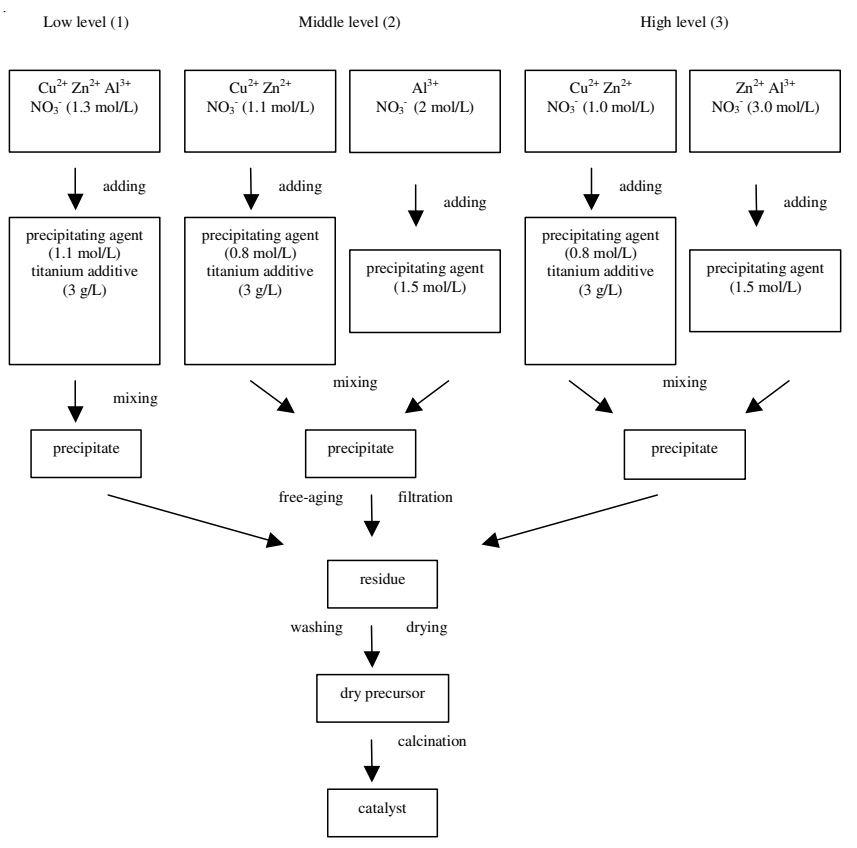

Fig. 1. Precipitating scheme used to prepare copper-based catalysts

Preparation of titanium additives: Anatase nanofibers were prepared via a hydrothermal reaction between an $\mathrm{HNO}_{3}$ solution and hydrogen titanate $\left(\mathrm{H}_{2} \mathrm{Ti}_{3} \mathrm{O}_{7}\right)$, which was neutral-
TABLE-2

STRUCTURE OF $\mathrm{L}_{9}\left(3^{4}\right)$ ORTHOGONAL STRUCTURE

\begin{tabular}{cccccc}
\hline Experiment & A & B & C & D & Result \\
\hline 1 & 1 & 1 & 1 & 1 & $\mathrm{R} 1$ \\
2 & 1 & 2 & 2 & 2 & R2 \\
3 & 1 & 3 & 3 & 3 & R3 \\
4 & 2 & 1 & 3 & 2 & R4 \\
5 & 2 & 2 & 1 & 3 & R5 \\
6 & 2 & 3 & 2 & 1 & R6 \\
7 & 3 & 1 & 2 & 3 & R7 \\
8 & 3 & 2 & 3 & 1 & R8 \\
9 & 3 & 3 & 1 & 2 & R9 \\
\hline
\end{tabular}

ized from trititanate nanofibers $\left(\mathrm{Na}_{2} \mathrm{Ti}_{3} \mathrm{O}_{7}\right)$ using $0.1 \mathrm{~mol} / \mathrm{L}$ $\mathrm{HCl}^{11,12}$. For example, $0.9 \mathrm{~g}$ of $\mathrm{H}_{2} \mathrm{Ti}_{3} \mathrm{O}_{7}$ was mixed with $90 \mathrm{~mL}$ of a $0.05 \mathrm{~mol} / \mathrm{L} \mathrm{HNO}_{3}$ solution, then transferred to a $100 \mathrm{~mL}$ Teflon-lined stainless steel autoclave and kept at $120{ }^{\circ} \mathrm{C}$ for $48 \mathrm{~h}$ to yield anatase nanofibers. The white precipitate in the autoclaved mixture was recovered and washed with deionized water until the $\mathrm{pH}$ value of the filtrate was approximately 7.0 and then dried at $70^{\circ} \mathrm{C}$ overnight.

Rutile nanofibers were prepared via a hydrothermal reaction between an $\mathrm{HNO}_{3}$ solution and hydrogen titanate ${ }^{12}$. For example, $0.9 \mathrm{~g}$ of $\mathrm{H}_{2} \mathrm{Ti}_{3} \mathrm{O}_{7}$ was mixed with $90 \mathrm{~mL}$ of a $2.65 \mathrm{~mol} / \mathrm{L} \mathrm{HNO}_{3}$ and then transferred to a $100 \mathrm{~mL}$ Teflonlined stainless steel autoclave and kept at $80{ }^{\circ} \mathrm{C}$ for $48 \mathrm{~h}$ to yield anatase nanofibers. The white precipitate in the autoclaved mixture was recovered and washed with deionized water until the $\mathrm{pH}$ value of the filtrate was 7 and subsequently dried at $70{ }^{\circ} \mathrm{C}$ overnight.

Octa-potassium titanate whiskers $\left(\mathrm{K}_{2} \mathrm{Ti}_{8} \mathrm{O}_{17}\right)$ were prepared by reaction of concentrated $\mathrm{KOH}$ and a titanium compound under hydrothermal conditions ${ }^{11}$. For example, a solution of $10.7 \mathrm{~g}$ of $\mathrm{TiOSO}_{4} \cdot \mathrm{xH}_{2} \mathrm{O}$ in $80 \mathrm{~mL}$ water was mixed with 100 $\mathrm{mL} 15 \mathrm{~mol} / \mathrm{L} \mathrm{KOH}$. The white suspension was then transferred to a $200 \mathrm{~mL}$ Teflon-lined stainless steel autoclave and kept at $200{ }^{\circ} \mathrm{C}$ for $48 \mathrm{~h}$ to yield octa-potassium titanate whiskers. The solid in the autoclaved mixture was recovered and washed with deionized water until the $\mathrm{pH}$ value of the filtrate was 7.0 and then dried at $70^{\circ} \mathrm{C}$ overnight. After grinding, each product was incorporated as an additive into the ternary $\mathrm{Cu}$ / $\mathrm{ZnO} / \mathrm{Al}_{2} \mathrm{O}_{3}$ catalysts.

Preparation of the copper-based catalysts: The copperbased catalysts were prepared by reverse co-precipitation ${ }^{13}$ according to the conditions listed in Tables 1 and 2. To mimic commercial catalysts, the molar ratio of $\mathrm{Cu} / \mathrm{Zn}$ was $2.2: 1$ and the content of $\mathrm{Al}_{2} \mathrm{O}_{3}$ and titanium additive were kept at 10 and 3 wt \%, respectively. During the co-precipitation, ultrasonic irradiation was supplied by an ultras cleaner (model KH400DB made in KunShan Hechuang Ultrasoic Co,. Ltd. Kunshan, Jiangsu, China) operating at $400 \mathrm{~W}$ and $40 \mathrm{kHz}$. The surfactant 
added in the solution of basic precipitating agents was OP-10 at a concentration of $50 \mathrm{~mL} / \mathrm{L}$. After precipitation, the suspension in the beaker was stirred and the final $\mathrm{pH}$ value was adjusted to 7 . If necessary, suspensions were combined and continuously stirred for $10 \mathrm{~min}$ at $75^{\circ} \mathrm{C}$. Then the suspension was maintained at the same temperature for $2 \mathrm{~h}$ to complete the free-aging step. The precipitate was washed with deionized water at $10{ }^{\circ} \mathrm{C}$ below the precipitating temperature until $\mathrm{NO}_{3}{ }^{-}$was not detected in the filtrate by a $1 \mathrm{wt} \%\left(\mathrm{C}_{6} \mathrm{H}_{5}\right)_{2} \mathrm{NH} /$ $\mathrm{H}_{2} \mathrm{SO}_{4}$ indicator ${ }^{14}$. The precipitate was then dried at $90{ }^{\circ} \mathrm{C}$ for at least $12 \mathrm{~h}$. After grinding, the precursors were calcined at $320^{\circ} \mathrm{C}$ in an atmosphere of air for $2 \mathrm{~h}$. The precursors prepared according to $\mathrm{L}_{9}\left(3^{4}\right)$ orthogonal design were designated PR1 to PR9 and the catalysts derived form precursors were designated Cat 1 to Cat9. The basic precipitating agent used in this work was $\mathrm{NaHCO}_{3}$ unless octa-potassium titanate was used as an additive and then $\mathrm{KHCO}_{3}$ replaced $\mathrm{NaHCO}_{3}$ to avoid metal ion exchange.

Sample characterization: The X-ray powder diffraction patterns were recorded on an ARL X'TRA X-ray powder diffractometer $\left(\mathrm{CuK}_{\alpha}\right.$ radiation) at a scanning rate of $5 \% \mathrm{~min}$. An SDT Q600 thermal analyzer was used to record the DTG patterns of the precursors in a flow of nitrogen at a heating rate of $10^{\circ} \mathrm{C} / \mathrm{min}$.

Temperature-programmed reduction (TPR) studies were carried out in a Netzsch STA449C thermo-analyzer using a gas mixture of $30 \mathrm{vol} \% \mathrm{H}_{2}$ in nitrogen at a flow of $20 \mathrm{~mL} /$ min. The reactor was heated from room temperature to $400{ }^{\circ} \mathrm{C}$ at a rate of $10^{\circ} \mathrm{C} / \mathrm{min}$. Typically, $20 \mathrm{mg}$ of catalyst powder was used as the sample. To study the reduction from $\mathrm{CuO}$ to $\mathrm{Cu}$ in the catalysts, the heat flow to unit mass of samples was measured. Meanwhile, transmission electron microscopy (TEM) was performed with a JEM-200CX instrument operated at $200 \mathrm{kV}$.

The specific surface area of the samples was calculated by the BET method from nitrogen adsorption isotherms at 77 K using a NOVA 3100 Quantachrome apparatus.

The catalytic activity of the catalysts for methanol synthesis was evaluated in a pressurized fixed-bed flow reactor system at 5.0 $\mathrm{MPa}, 240{ }^{\circ} \mathrm{C}$ and a space velocity of $10,000 \mathrm{~mL} /$ $\mathrm{g}$ cat h. Four milliliters of catalyst particles of 16-40 mesh were charged into the reactor. The composition of the gas feed was $\mathrm{CO} / \mathrm{CO}_{2} / \mathrm{H}_{2} / \mathrm{N}_{2}=15 / 5 / 60 / 20$ (vol \%). Before the gas feed was let in, the catalyst was reduced with $5 \mathrm{vol} \% \mathrm{H}_{2} / \mathrm{N}_{2}$ under normal pressure. The heating procedure of the catalyst bed was as follows: from room temperature to $130{ }^{\circ} \mathrm{C}$ at a rate of $60{ }^{\circ} \mathrm{C} / \mathrm{h}$; heating to $170{ }^{\circ} \mathrm{C}$ at a rate of $20^{\circ} \mathrm{C} / \mathrm{h}$; heating to 200 ${ }^{\circ} \mathrm{C}$ at a rate of $5{ }^{\circ} \mathrm{C} / \mathrm{h}$; heating to $240{ }^{\circ} \mathrm{C}$ at a rate of $20^{\circ} \mathrm{C} / \mathrm{h}$; and finally holding at $240^{\circ} \mathrm{C}$ for $2 \mathrm{~h}$. The entire reduction procedure took $c a .14 \mathrm{~h}$. After initial evaluation of catalytic performance, the catalysts were reheated at $350{ }^{\circ} \mathrm{C}$ for $5 \mathrm{~h}$ and then cooled to $240{ }^{\circ} \mathrm{C}$ to re-evaluate the catalytic performance. The crude methanol product was collected by condensation at $0{ }^{\circ} \mathrm{C}$ and analyzed out of line on a chromatograph equipped with a GDX-103 column and a TCD detector.

\section{RESULTS AND DISCUSSION}

Catalytic performance of catalysts: Table- 3 lists the catalytic performance of copper-based catalysts designed by orthogonal experiments. According to the data, higher yields of crude methanol in the initial catalytic process were obtained using Cat 8 and Cat 9 and the highest purity of crude methanol was achieved with Cat 7. After catalysts were heated at $350^{\circ} \mathrm{C}$ for $5 \mathrm{~h}$, both the catalytic activity and the purity of crude methanol clearly decreased. However, the yield and purity of methanol decreased less with Cat 7 and Cat 8 which had higher thermal stability.

Because the experimental design was orthogonal, it was possible to separate the effect of each parameter at different levels by range analysis. For example, the effect of precipitating temperature on the yield of crude methanol in the initial catalytic process at Level 1, Level 2 and Level 3 could be calculated by averaging the data for experiments 1-3, 4-6 and 7-9, respectively (Table-2). The effect of other parameters could then be calculated in a similar manner. The results for each parameter on catalytic activity and thermal stability are shown in Tables 4-6.

As can be observed in Table-4, the highest maximumminimum values for the yield of crude methanol in the initial catalytic process belonged to precipitating temperature. Therefore, precipitating temperature was a significant parameter affecting initial catalytic yield in methanol synthesis. Specifically, high precipitating temperature was better for the preparation of copper-based catalysts. In general, the effect of precipitating temperature can be explained by higher temperatures allowing the precipitation to proceed under less oversaturated conditions and thus at a lower rate. This effect resulted in a more uniform precipitate in which $\mathrm{Cu}$ and $\mathrm{Zn}$ were homogeneously distributed ${ }^{15}$.

\begin{tabular}{|c|c|c|c|c|c|}
\hline \multicolumn{6}{|c|}{$\begin{array}{c}\text { TABLE-3 } \\
\text { CATALYTIC ACTIVITY OF DIFFERENT CATALYSTS }\end{array}$} \\
\hline Sample & $\begin{array}{l}\text { Initial methanol yield } \\
\qquad\left(\mathrm{g} \mathrm{mL}^{-1} \mathrm{~h}^{-1}\right)\end{array}$ & $\begin{array}{c}\text { Initial methanol purity } \\
(\%)\end{array}$ & $\begin{array}{l}\text { Methanol yield after } \\
\text { heat process }\left(\mathrm{g} \mathrm{mL}^{-1} \mathrm{~h}^{-1}\right)\end{array}$ & $\begin{array}{l}\text { Methanol purity after } \\
\text { heat process }(\%)\end{array}$ & $\begin{array}{l}\text { Activity loss (per cent of } \\
\text { initial activity lost) }(\%)\end{array}$ \\
\hline Cat 1 & 1.18 & 93.5 & 0.86 & 85.4 & 27.1 \\
\hline Cat 2 & 1.23 & 95.0 & 0.99 & 87.1 & 19.5 \\
\hline Cat 3 & 1.16 & 93.8 & 0.93 & 89.7 & 19.8 \\
\hline Cat 4 & 1.08 & 96.9 & 0.85 & 88.0 & 21.3 \\
\hline Cat 5 & 1.16 & 90.0 & 0.80 & 85.2 & 31.0 \\
\hline Cat 6 & 1.18 & 96.4 & 0.89 & 88.2 & 24.6 \\
\hline Cat 7 & 1.28 & 99.2 & 1.16 & 92.2 & 9.4 \\
\hline Cat 8 & 1.34 & 96.5 & 1.16 & 90.8 & 13.4 \\
\hline Cat 9 & 1.36 & 94.9 & 1.01 & 86.7 & 25.7 \\
\hline
\end{tabular}


TABLE-4

EFFECT OF EACH PARAMETER ON YIELD OF CRUDE METHANOL IN THE INITIAL CATALYTIC PROCESS

\begin{tabular}{clcccc}
\hline \multirow{2}{*}{ Effect } & \multicolumn{1}{c}{ Parameter } & \multicolumn{3}{c}{ Yield of crude methanol in the initial catalytic process $\left(\mathrm{g} \mathrm{mL}^{-1} \mathrm{~h}^{-1}\right)$} \\
\cline { 2 - 6 } & & Level 1 & Level 2 & Level 3 & Maximum-minimum \\
\hline A & Precipitating temperature & 1.19 & 1.14 & 1.33 & 0.19 \\
B & Precipitating mode & 1.18 & 1.24 & 1.23 & 0.06 \\
C & Additive & 1.23 & 1.23 & 1.19 & 0.04 \\
D & Precipitating environment & 1.23 & 1.22 & 1.20 & 0.03 \\
\hline
\end{tabular}

Although which copper-based active sites exists in these catalysts is still hotly debated, it is irrefutable that both pure copper and pure zinc oxide are inactive in methanol synthesis. However, copper and zinc oxide components form the basis for methanol synthesis from syngas ${ }^{16}$. High precipitating temperatures promote precursors with a high mixing degree and may strengthen this synergistic effect between $\mathrm{Cu}$ and $\mathrm{Zn}$.

The data given in Table-5 illustrate that the additive is the main parameter affecting the purity of crude methanol obtained in the initial catalytic process, Rutile nanofiber is clearly a better choice than other titanium additives. However, the statistically significant difference between the additive and other parameters was not obvious. It could therefore be presumed that ternary $\mathrm{Cu} / \mathrm{ZnO} / \mathrm{Al}_{2} \mathrm{O}_{3}$ catalysts have high selectivity in methanol synthesis. The incorporation of rutile nanofiber as an additive to enhance the selectivity for methanol is thus limited.

As shown in Table-6, both precipitating temperature and the additive were significant parameters affecting the thermal stability in the catalytic process. As mentioned above, high precipitating temperature resulted in a more uniform precipitate and a high mixing degree, both of which enhanced catalytic activity. Considering the additive, both rutile nanofibers and octa-potassium titanate whiskers were functional additives that increased the thermal stability of the catalysts. According to the XRD patterns of calcined catalysts, both of the additives played a role in protecting the active components in the catalysts.

Characterization of precursors: The DTG patterns of PR 1 to PR 9 contained three main phases (Fig. 2). The typical DTG pattern of the hydrotalcite-like phase $\left((\mathrm{Cu}, \mathrm{Zn})_{6} \mathrm{Al}_{2} \mathrm{CO}_{3}(\mathrm{OH})_{16} \cdot 4 \mathrm{H}_{2} \mathrm{O}\right)$ was characterized by a strong endothermic peak at $150{ }^{\circ} \mathrm{C}$ and a weak endothermic peak at $220{ }^{\circ} \mathrm{C}$. The DTG pattern of the malachite-like phase $\left((\mathrm{Cu}, \mathrm{Zn})_{2} \mathrm{CO}_{3}(\mathrm{OH})_{2}\right)$ was a single peak at $380^{\circ} \mathrm{C}^{15}$. The broad

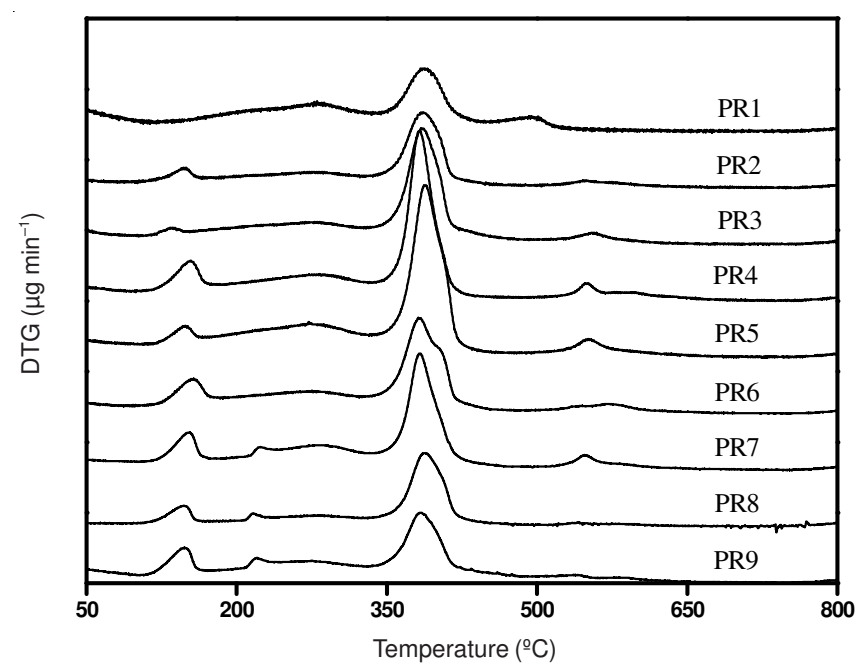

Fig. 2. DTG patterns of the catalyst precursors

endothermic peak between 250 and $320^{\circ} \mathrm{C}$ could be ascribed to the malachite phase $\left(\mathrm{Cu}_{2}(\mathrm{OH})_{2} \mathrm{CO}_{3}\right)^{17}$. It was clear that no endothermic peak for $(\mathrm{Cu}, \mathrm{Zn})_{6} \mathrm{Al}_{2} \mathrm{CO}_{3}(\mathrm{OH})_{16} \cdot 4 \mathrm{H}_{2} \mathrm{O}$ was present in $\mathrm{PR} 1$ and the weak endothermic peak of $(\mathrm{Cu}, \mathrm{Zn})_{6} \mathrm{Al}_{2} \mathrm{CO}_{3}(\mathrm{OH})_{16} \cdot 4 \mathrm{H}_{2} \mathrm{O}$ at $220{ }^{\circ} \mathrm{C}$ was not be observed in PR 2 through PR 6. Combined with the parameter analysis in Tables 4-6, it was presumed that this difference was due to precipitating temperature. When the precipitating temperature was below $75^{\circ} \mathrm{C}$, the difference in the value of the solubility product constants between precipitating components, particularly $\mathrm{Cu}^{2+}$ and $\mathrm{Zn}^{2+}$, decreased the mixing degree of the components in the precursors. Therefore, it could be presumed that the total content of $(\mathrm{Cu}, \mathrm{Zn})_{6} \mathrm{Al}_{2} \mathrm{CO}_{3}(\mathrm{OH})_{16} \cdot 4 \mathrm{H}_{2} \mathrm{O}$ and $(\mathrm{Cu}, \mathrm{Zn})_{2} \mathrm{CO}_{3}(\mathrm{OH})_{2}$ decreased and the pure malachite phase increased with decreasing precipitation temperature.

\begin{tabular}{clcccc} 
& \multicolumn{5}{c}{ TABLE-5 } \\
& EFFECT OF EACH PARAMETER ON PURITY OF CRUDE METHANOL IN THE INITIAL CATALYTIC PROCESS \\
\hline \multirow{2}{*}{ Effect } & \multicolumn{1}{c}{ Parameter } & \multicolumn{4}{c}{ Purity of crude methanol in the initial catalytic process (\%) } \\
\cline { 2 - 6 } & & Level 1 & Level 2 & Level 3 & Maximum-minimum \\
\hline A & Precipitating temperature & 94.1 & 94.4 & 96.9 & 2.8 \\
B & Precipitating mode & 96.5 & 93.8 & 95.0 & 2.7 \\
C & Additive & 92.8 & 96.9 & 95.7 & 4.1 \\
D & Precipitating environment & 95.5 & 95.6 & 94.3 & 1.3 \\
\hline
\end{tabular}

TABLE-6

EFFECT OF EACH PARAMETER ON THERMAL STABILITY OF COPPER-BASED CATALYSTS AFTER HEATING

\begin{tabular}{clccc}
\hline \multirow{2}{*}{ Effect } & \multicolumn{1}{c}{ Parameter } & \multicolumn{2}{c}{ Thermal stability after heating (\%) } \\
\cline { 3 - 5 } & & Level 1 & Level 2 & Level 3 \\
\hline A & Precipitating temperature & 22.1 & 25.6 & 16.2 \\
B & Precipitating mode & 19.3 & 21.3 & 23.4 \\
C & Additive & 27.9 & 17.8 & 18.2 \\
D & Precipitating environment & 21.7 & 22.2 & 20.1 \\
\hline
\end{tabular}


It should be noted that there was a small endothermic peak between 450 and $600{ }^{\circ} \mathrm{C}$ in the DTG patterns of PR 1 to PR 7. We suggested this peak belonged to the decomposition of nitrates ${ }^{18}$. Although a $1 \mathrm{wt} \%\left(\mathrm{C}_{6} \mathrm{H}_{5}\right)_{2} \mathrm{NH} / \mathrm{H}_{2} \mathrm{SO}_{4}$ indicator was used to detect $\mathrm{NO}_{3}{ }^{-}$in the filtrate during the washing treatment, the content of nitrate in the precursors might have been beyond the limit of detection. It was previously reported that nitrate residue present in the calcined catalysts inhibited the interaction of the $\mathrm{CuO}$ phase with the $\mathrm{ZnO}$ matrix and decreased $\mathrm{Cu}$-dispersion ${ }^{19}$, negatively impacting methanol synthesis. The temperature of the washing treatment is related to precipitating temperature and no endothermic peak for nitrates were observed in PR 8 and PR 9. Therefore, higher washing water temperature could increase the solubility of ions and remove nitrates deposited in the precursors.

The XRD patterns of PR 1 to PR 9 are shown in Fig. 3. According to the results of automatic identification, three main phases were observed: $(\mathrm{Cu}, \mathrm{Zn})_{6} \mathrm{Al}_{2} \mathrm{CO}_{3}(\mathrm{OH})_{16} \cdot 4 \mathrm{H}_{2} \mathrm{O}$, $(\mathrm{Cu}, \mathrm{Zn})_{2} \mathrm{CO}_{3}(\mathrm{OH})_{2}$ and $\mathrm{Cu}_{2}(\mathrm{OH})_{2} \mathrm{CO}_{3}$. The narrow XRD peak at $11.77^{\circ}$ ascribed to $(\mathrm{Cu}, \mathrm{Zn})_{6} \mathrm{Al}_{2} \mathrm{CO}_{3}(\mathrm{OH})_{16} \cdot 4 \mathrm{H}_{2} \mathrm{O}$ was not observed in PR 1, which was consistent with the results shown in the DTG pattern. Although three types of titanium were incorporated as additives, no strong diffraction lines ascribed to titanium were detected. The XRD patterns of pure titanium additives are presented in Fig. 4 and are in good agreement with those reported by Yuan ${ }^{20}$ and $\mathrm{Zhu}^{12}$. It is reasonable to presume that a small amount of additives could be homogeneously distributed in the precursors during co-precipitation and might have been present as amorphous material.

Characterization of calcined catalysts: Cat 1 to Cat 9 were obtained after calcination of the precursors at $320^{\circ} \mathrm{C}$ for 2 h. As shown in Fig. 5, XRD peaks at 35.25, 38.40 and $48.59^{\circ}$ were characteristic of $\mathrm{CuO}$ and the crystal sizes of $\mathrm{CuO}$ calculated by the method of line broadening based on the Scherrer equation are shown in Table-7. Only weak diffraction lines at $31.63^{\circ}$ could be ascribed to $\mathrm{ZnO}$ and characteristic peaks of $\mathrm{Al}_{2} \mathrm{O}_{3}$ were not observed, most likely owing to the small quantity of amorphous $\mathrm{ZnO}$ and $\mathrm{Al}_{2} \mathrm{O}_{3}$. It was noteworthy that the characteristic peaks ascribed to $(\mathrm{Cu}, \mathrm{Zn})_{2} \mathrm{CO}_{3}(\mathrm{OH})_{2}$ and $\mathrm{Cu}_{2} \mathrm{CO}_{3}(\mathrm{OH})_{2}$ were still present in Cat 3, Cat 5 and Cat 8 . These hydroxy carbonate phases were likely residues originating from the precursor that were not completely decomposed during calcination. According to Schlögl et al. ${ }^{21}$, such residual carbonate might be responsible for the formation of highly active sites, leading to high catalytic activity. Combined with the analysis of thermal stability in Table-6, we suggested that

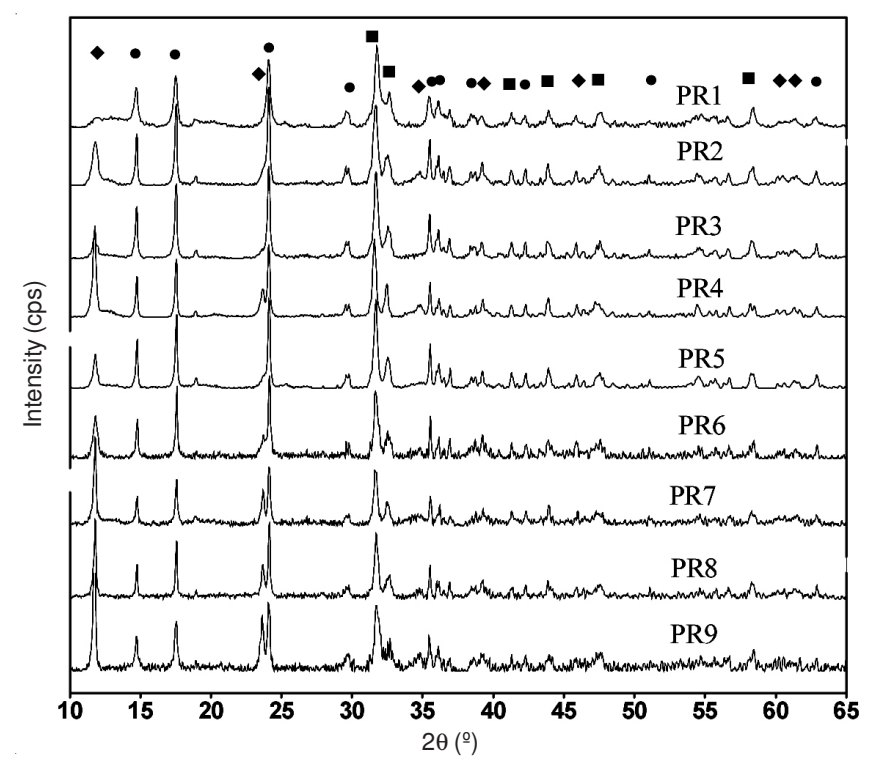

- $(\mathrm{Cu}, \mathrm{Zn})_{6} \mathrm{Al}_{2} \mathrm{CO}_{3}(\mathrm{OH})_{16} \cdot 4 \mathrm{H}_{2} \mathrm{O} ; \bullet(\mathrm{Cu}, \mathrm{Zn})_{2} \mathrm{CO}_{3}(\mathrm{OH})_{2} ; \boldsymbol{\bullet} \mathrm{Cu}_{2}(\mathrm{OH})_{2} \mathrm{CO}_{3}$

Fig. 3. XRD patterns of the catalyst precursors

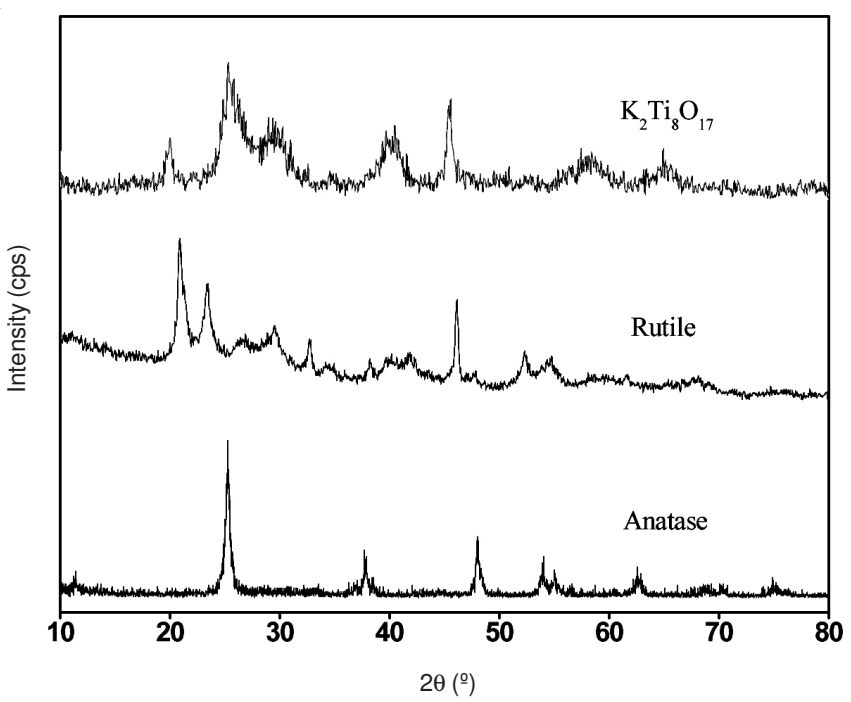

Fig. 4. XRD patterns of titanium additives

rutile nanofibers and octa-potassium titanate incorporated as functional additives effectively protected these residual carbonates $^{22,23}$. However, the relative intensities of XRD peaks ascribed to $(\mathrm{Cu}, \mathrm{Zn})_{2} \mathrm{CO}_{3}(\mathrm{OH})_{2}$ and $\mathrm{Cu}_{2} \mathrm{CO}_{3}(\mathrm{OH})_{2}$ were different and residual carbonate in Cat 8 appeared as well-defined crystalline phases. This phenomenon was related to the precipitating

\begin{tabular}{|c|c|c|c|c|c|}
\hline \multirow{3}{*}{ Sample } & \multicolumn{5}{|c|}{$\begin{array}{c}\text { TABLE-7 } \\
\text { BET SPECIFIC AREA, PORE STRUCTURE AND CuO CRYSTAL SIZE FOR CALCINED CATALYSTS }\end{array}$} \\
\hline & \multirow{2}{*}{$\begin{array}{l}\text { BET specific area } \\
\left(\mathrm{m}^{2} \mathrm{~g}^{-1}\right)\end{array}$} & \multirow{2}{*}{$\begin{array}{l}\text { Average pore } \\
\text { diameter (nm) }\end{array}$} & \multirow{2}{*}{$\begin{array}{l}\text { Pore volume } \\
\left(\mathrm{cm}^{3} \mathrm{~g}^{-1}\right)\end{array}$} & \multicolumn{2}{|c|}{$\mathrm{CuO}$ crystal size $(\mathrm{nm})$} \\
\hline & & & & $2 \theta=35.25^{\circ}$ & $2 \theta=38.40^{\circ}$ \\
\hline Cat 1 & 90.1 & 12.3 & 0.2771 & 8.1 & 7.1 \\
\hline Cat 2 & 75.4 & 7.0 & 0.131 & 8.9 & 8.3 \\
\hline Cat 3 & 48.0 & 10.8 & 0.1297 & 9.3 & 7.1 \\
\hline Cat 4 & 54.4 & 11.9 & 0.1617 & 9.1 & 7.7 \\
\hline Cat 5 & 57.6 & 11.5 & 0.1650 & 10.3 & 7.9 \\
\hline Cat 6 & 43.76 & 14.8 & 0.1616 & 8.7 & 8.4 \\
\hline Cat 7 & 57.9 & 13.2 & 0.1915 & 8.9 & 7.8 \\
\hline Cat 8 & 55.1 & 11.5 & 0.1591 & 9.0 & 7.5 \\
\hline Cat 9 & 58.3 & 12.2 & 0.1779 & 8.7 & 9.2 \\
\hline
\end{tabular}




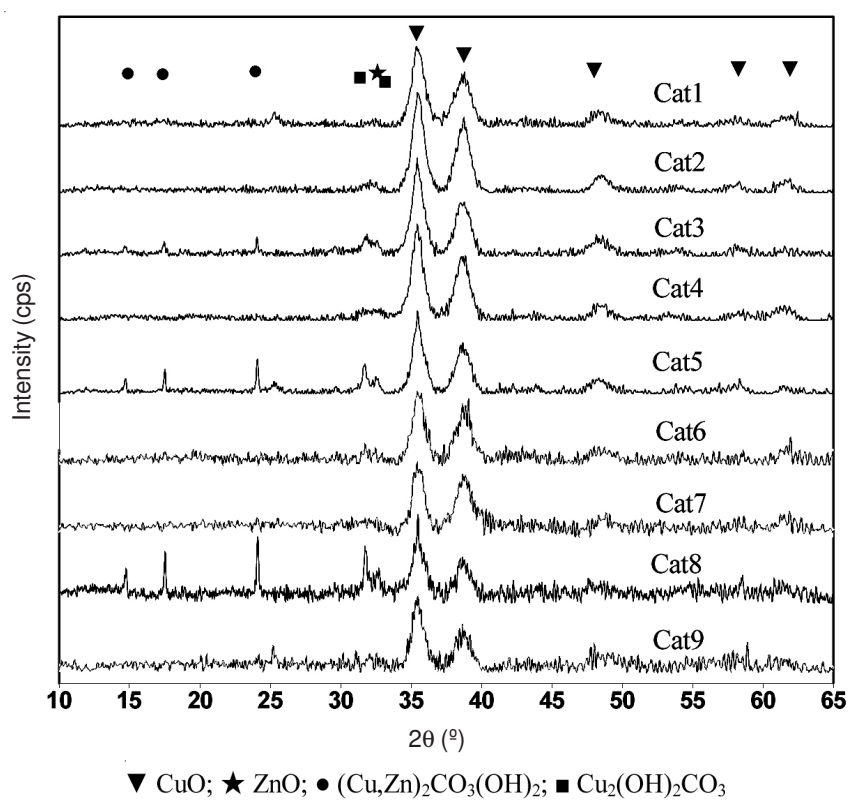

Fig. 5. XRD patterns of the calcined catalysts

temperature. High precipitating temperature was conducive to the mixing of each component in the catalyst, which strengthened the synergistic effect between precursors and additive. Therefore, more pure and mixed malachite grains remained to promote catalytic activity in methanol synthesis, especially after heating.

The TPR patterns of Cat 1 to Cat 9 (Fig. 6) were recorded using catalyst powders. The strong reduction peak at 205-220 ${ }^{\circ} \mathrm{C}$ appeared as two overlapping peaks, indicating at least two types of CuO-related species in the catalysts. The peak at low temperature could be associated with $\mathrm{CuO}$ interacting with $\mathrm{ZnO}$ and other metal additives, while the high temperature peak belonged to non-interacting $\mathrm{CuO}$ species. An even flatter reduction peak at $240-250^{\circ} \mathrm{C}$ was ascribed to a small amount of sintering of the $\mathrm{CuO}$ during calcination, increasing the difficulty to reduce this material.

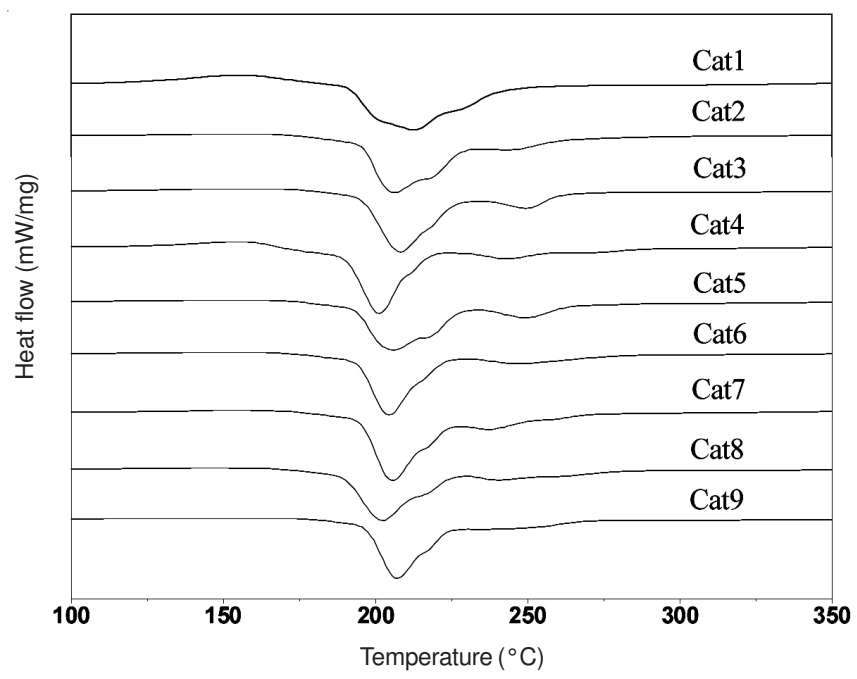

Fig. 6. TPR patterns of Cat 1-Cat 9

Thus, most of the $\mathrm{CuO}$ in $\mathrm{Cat} 1$ to Cat 3 was reduced at a much higher temperature than that for the other samples. This phenomenon was ascribed to the precipitating temperature during co-precipitation. According to Lee et al. ${ }^{19}, \mathrm{CuO}$ can be easily reduced at relatively low temperature due to the synergistic effect between $\mathrm{CuO}$ and $\mathrm{ZnO}$ as well as to the support of other metal additives. A lower precipitating temperature decreased the mixing degree of components in the catalysts and the synergistic effect weakened in Cat 1 to Cat 3 . Therefore, the reduction temperature of $\mathrm{CuO}$ might reflect the degree of synergism in the catalysts and thus the catalytic activity in methanol synthesis.

The strong reduction peak of Cat 8 at $205{ }^{\circ} \mathrm{C}$ was lower than any other sample and its weak reduction peak at 240$250{ }^{\circ} \mathrm{C}$ was obscured. We presumed that the TPR pattern of Cat8 was consistent with its catalytic performance shown in Table-3. For comparison, although Cat9 showed the highest yield of crude methanol in the initial catalytic process, $25.7 \%$ of the initial catalytic activity was lost after heating at $350^{\circ} \mathrm{C}$ for $2 \mathrm{~h}$. It was thus reasonable to presume that a higher reduction temperature decreased synergism in the catalyst and negatively affected the retention of catalytic activity.

The TEM micrographs shown in Fig. 7 illustrate the changes in sample morphology before and after calcination. Cat 8 was chosen for more detailed study because of both its catalytic activity and thermal stability in methanol synthesis. From Figs. 7a-b, precursor free-aged for $2 \mathrm{~h}$ contained mainly large clusters of needles (3-7 nm width, 100-200 nm length) and a small amount of irregular platelet-shaped small crystals (10-25 nm diameter). After being calcined at $320{ }^{\circ} \mathrm{C}$ for $2 \mathrm{~h}$, the needle-shaped crystals cracked into small particles (approximately $10 \mathrm{~nm}$ diameter, Figs. 8c-d), indicating excellent $\mathrm{Cu}$-dispersion in the calcined sample. However, it was clear that successive fragmentation had no effect on the overall shape of the crystallites. This result was consistent with the report of Baltes et al. ${ }^{24}$, who studied the changes in catalyst morphology with preparation steps. The area in the white frame in Fig. 7c provides a more detailed view of the irregular platelet-shaped small crystals that were unchanged and that could be detected in the XRD pattern of Cat 8. a

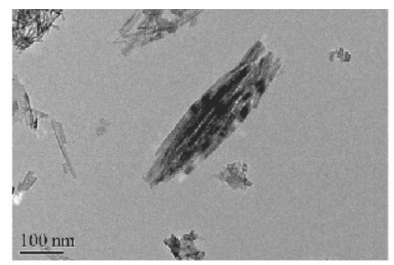

c

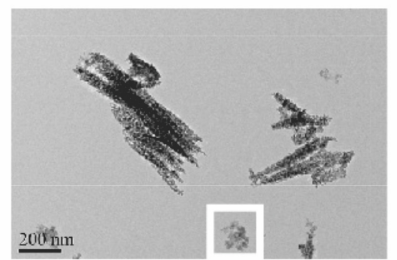

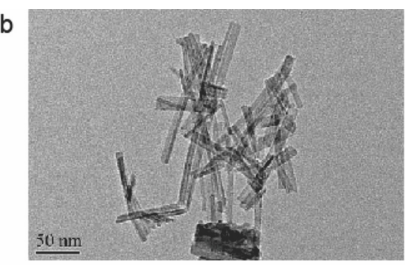

d

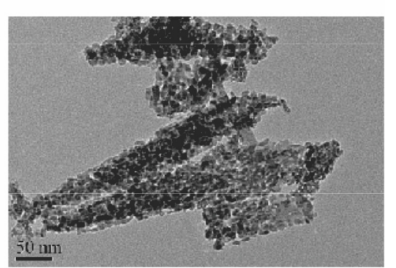

Fig. 7. TEM images of Cat 8: (a) and (b) catalyst precursor free-aged for 2 $\mathrm{h},(\mathrm{c})$ and (d) catalyst calcined at $320^{\circ} \mathrm{C}$ for $2 \mathrm{~h}$

Table-7 lists BET specific area, pore structure and $\mathrm{CuO}$ crystal size of Cat 1 to Cat 9 . The data for pore structure and BET specific area were collected using catalyst particles of 16-40 mesh. According to the data, the difference in the $\mathrm{CuO}$ 
crystal sizes was small, with Cat 1 containing the smallest $\mathrm{CuO}$ crystals. This result was believed to be caused by low precipitating temperature ${ }^{25}$ and ultrasonic treatment ${ }^{8,26}$ Tables 1 and 2 inhibited the growth of particles during co-precipitation.

The density of catalyst particles in present work was controlled at the same level in the molding process. Therefore, the higher BET specific area and larger pore volume of Cat 1 were likely derived from its small precipitation particles and these favorable features were conducive for gas adsorption and diffusion in the catalytic process. However, Cat 1 did not show excellent catalytic performance (Table-3). Combined with the previous analysis, we believe that a high mixing degree was critical for catalytic performance: only on this basis could high specific surface area and larger pore volume act as favorable features for catalysis. For comparison, although the BET specific area and pore volume of Cat 8 were smaller than Cat 1, a lower content of pure malachite phase and a lower reduction temperature indicated that each component in Cat8 had a higher mixing degree and stronger synergistic effect.

\section{Conclusion}

Generally speaking, the structural and catalytic properties of catalysts are affected by all the parameters of the coprecipitation. In this study, $\mathrm{Cu} / \mathrm{ZnO} / \mathrm{Al}_{2} \mathrm{O}_{3}$ catalysts modified with small amounts of titanium additives were prepared using orthogonal experimental design and detailed correlations between experimental parameters, properties of catalysts and catalytic performance were investigated. High precipitating temperature was found to promote precursors with fine interdispersion of the metallic elements and these precursors contained more rosasite and hydrotalcite-like phases according to DTG analysis. After calcination, $\mathrm{CuO}$ was easily reduced at lower temperatures, indicating a strong interaction with $\mathrm{ZnO}$ and other metal additives. Although low precipitating temperature combined with ultrasonic treatment could inhibit the growth of precipitation particles and provide larger BET specific area for catalysts, we suggested that strong synergistic effects in the catalysts were more important to catalytic performance.

Residual hydroxy carbonates were observed in several calcined catalysts. As previously reported ${ }^{21,24}$, such residues presumably facilitated the formation of highly active sites during reduction and greatly enhanced catalytic performance. Because of identical calcination conditions of $320^{\circ} \mathrm{C}$ for $2 \mathrm{~h}$, we believed that these remaining malachite-type grains were related to rutile nanofibers and octa-potassium titanate whiskers. Both of the titanium additives were high-temperature-resistant materials ${ }^{22,23}$. The synergistic effect between precursors and additives was established during co-precipitation. From the difference observed in the relative intensities of XRD peaks, high precipitating temperature was favorable for increasing this synergistic effect.

Cat 7 and Cat 8 showed high crude methanol yields in the initial catalytic process. Their activity loss after heat treatment was also less than that in other samples, indicating higher thermal stability synthesis of methanol.

\section{REFERENCES}

1. S. Schimpf and M. Muhler, In ed.: K.P. de Jong, Synthesis of Solid Catalysts, Wiley-Verlag GmbH \& Co. KGaA Publ, Weinheim, Ch. 15, p. 329 (2009).

2. M. Maack, H.F. Jensen, S. Sckerl, J.H. Larsen and I. Chorkendorff, Top. Catal., 22, 151 (2003).

3. I.M. Cabrera, M.L. Granados and J.L.G. Fierro, Catal. Lett., 84, 153 (2002).

4. N. Kanoun, M.P. Astier and G.M. Pajonk, Catal. Lett., 15, 231 (1992).

5. J.T. Li, W.D. Zhang, L.Z. Gao, P.Y. Gu, K.Q. Sha and H.L. Wan, Appl. Catal. A. Gen., 165, 411 (1997).

6. N. Nomura, T. Tagawa and S. Goto, Appl. Catal. A, 166, 321 (1998).

7. L. Liu, T.S. Zhao, Q.X. Ma and Y.F. Shen, J. Nat. Gas Chem., 18, 375 (2009).

8. J.L. Li and T. Inui, Appl. Catal. A. Gen., 139, 87 (1996).

9. F. Meshkini, M. Taghizadeh and M. Bahmani, Fuel, 89, 170 (2010).

10. M. Edrissi, M. Soleymani and S. Akbari, Synth. React. Inorg. MetalOrg. Nano-Metal Chem., 41, 1282 (2011).

11. D.J. Yang, Z.F. Zheng, H.W. Liu, H.Y. Zhu, X.B. Ke, Y. Xu, D. Wu and Y. Sun, J. Phys. Chem, C, 112, 16275 (2008).

12. H.Y. Zhu, Y. Lan, X.P. Gao, S.P. Ringer, Z.F. Zheng, D.Y. Song and J.C. Zhao, J. Am. Chem. Soc., 127, 6730 (2005).

13. F. Arena, G. Italiano, K. Barbera, G. Bonura, L. Spadaro and F. Frusteri, Catal. Today, 143, 80 (2009).

14. H. Niklas and F. Vogel, Z. Pflanzenernahr. Dung. Bodenkd., 3, 323 (1924).

15. J.L. Li and T. Inui, Appl. Catal. A, 137, 105 (1996).

16. X.J. Guo, L.M. Li, S.M. Liu, G.L. Bao and W.H. Hou, J. Fuel Chem. Technol., 35, 329 (2007).

17. N. Koga, T. Tatsuoka and Y. Tanaka, J. Therm. Anal. Calorim., 95, 483 (2009).

18. B. Bems, M. Schur, A. Dassenoy, H. Junkes, D. Herein and R. Schlögl, Chem. Eur. J., 9, 2039 (2003).

19. K.W. Jun, W.J. Shen, K.S. Rama Rao and K.W. Lee, Appl. Catal. A, 174, 231 (1998).

20. Z.Y. Yuan, X.B. Zhang and B.L. Su, Appl. Phys. A, 78, 1063 (2004).

21. M. Schur, B. Bems, A. Dassenoy, I. Kassatkine, J. Urban, H. Wilmes, O. Hinrichsen, M. Muhler and R. Schlögl, Angew. Chem. Int. Ed., 42, 3815 (2003).

22. S. Zhao, L.Y. Qiu and S. Liu, Adv. Mater. Res., 150-151, 620 (2011).

23. H. Gulledge, Ind. Eng. Chem., 52, 117 (1960).

24. C. Baltes, S. Vukojevic and F. Schüth, J. Catal., 258, 334 (2008).

25. J.P. Cheng, R. Ma, X. Chen, D. Shi, F. Liu and X.B. Zhang, Cryst. Res. Technol., 46, 723 (2011).

26. M. Sivakumar, A. Gedanken, Z.Y. Zhong and L.W. Chen, New. J. Chem., 30, 102 (2006). 